\title{
Developing Internet Protocol Television and Future Broadcasting Platforms: A Literature Review
}

\section{Introduction}

The purpose of this literature review is to examine fundamental research that has been undertaken in the field of Internet protocols. It will look at technology, cultural knowledge, and economic factors for Māori in order to explore the development of Internet protocol television (IPTV) and future broadcasting platforms.

Furthermore, this review seeks to obtain relevant information and research in order to critically appraise studies and directly use the information to identify relevant areas for Māori; formulate questions for further research into the development of IPTV and future broadcasting and to synthesise the results in a summary to demonstrate what is known and what is not known about the development of IPTV for Māori.

In order to understand the implications of developing IPTV broadcasting technologies for Māori, it is important to examine a global overview, from digital distribution of television on various platforms - the threats and opportunities of converging communications for conventional Māori broadcasters, independent Māori production companies, Māori information technology businesses, iwi, hapū and whānau.

With the developments and rapid technological advances in broadcasting video and audio content being delivered over the Internet, it is important to look at the advantages and threats that will impact on Māori. These various threats and advantages include protection of Māori cultural knowledge and 
representation both in Aotearoa New Zealand and the global marketplace.

The threats for Māori are based around the struggle and control over cultural knowledge and representation within technological structures including the rapid distribution platforms that the world wide web provides.

It is important to examine the technological aspects that may impact on the development of IPTV for Māori. In order to examine these implications, one should examine literature, which provides arguments for and against the developments of information technologies and broadcasting developments for Māori domestically alongside a global overview of the development of indigenous peoples in these areas. They both act as indicators for how Māori might develop IPTV.

\section{Cultural Knowledge}

When considering the key factors that Māori need to consider to develop IPTV and future broadcasting platforms, cultural knowledge relating to information technologies is essential. The literature investigates the benefits and the threats that impact on indigeous cultures both globally and for Māori. This includes representation, exploitation, intellectual property, legalities, governance and ethical issues.

Isekes-Barnes (2003) examines indigenous peoples adoption and participation in information technologies. The concerning issues raised are based around the impact of globalisation, the struggle for power and control over representation of indigenous people within these technologies. Topics covered provide both theoretical and empirical information and originate from a broad cross section of research communities and practitioners; about half are indigenous contributors from around the world. There is a cross section of case studies of indigenous people with five distinct sections within this book (Isekes-Barnes), which will be reviewed in summary below. 
The first section poses questions around indigenous adoption and participation in information technologies, the issues of globalisation and the concerns of power, control and representation.

The second section 'Technology in Education' investigates the way which indigenous people utilise information technology in education. It offers perspectives on how information technologies can help and support indigenous people that are marginalised as a result of isolation, culturally inappropriate programmes and ways which indigenous people learn.

Section three, 'Cultural Preservation and Revitalisation', explores how the multi media technologies, including video and audio platforms, alongside digital archival and storage tools, can provide opportunities for indigenous people to preserve and revitalise their languages and cultures.

The fourth section 'Applications Transforming Communities' looks at information technology software applications and how they can transform indigenous communities. For example how financial and accounting packages help indigenous people to run their own businesses.

Finally, section five 'Linking Communities and Improving Access' explores how information technology can improve communication between global indigenous communities and how information technology is helping to overcome geographical boundaries and link communities.

According to Iseke-Barnes (2003), cyberspace and information technologies are limitless in their potential as transmission platforms for the dominant society to continue colonisation practices.

Additionally, Mander (1991) offers information and arguments for the developments and use of information technologies by indigenous people. Mander primarily looks at the effects of information technology on indigenous peoples of America and Canada. Mander argues the adoption of 
information technology by indigenous peoples can lead to exploitation of their culture by the Western world.

Mander (1991) argues that this is achieved by means of colonisation and control over the technological platforms for the distribution of information. He states that the rapid spread of information technology, while hard to stop now, has led to misrepresentations of cultures. Mander notes that information technology risks the integrity of indigenous cultures by homogenising cultural identities and feeding into negative stereotypical cultural characterisations.

Furthermore, Mander (1991) ascertains that unrestricted access to information encourages the unauthorised use of copyright material and asks where indigenous cultures find the balance between the rights of intellectual, cultural property holders with the rights of those seeking access to information for educational or cultural purposes or even worse for pure racial colonisation and dominance.

An example by Durie (1997) illustrates the homogenisation of Māori culture. For example the term 'Māori' itself has the tendency to be used as a homogenising term for all of the Māori tribal groups, thereby obscuring the distinguishing the characteristics of each individual iwi and hapū.

In addition to providing a global perspective on the impact of information technology for indigenous cultures, Kamira's (2003) paper provides a chronological summary of important Information Technology developments in a global context, relating these developments to what was happening for Māori. She argues that in order to examine the impact of IT whether positive or negative, short term or long term one, has to take into account the contextual environment in which they are being looked at.

Kamira (2003), states that the lesson for indigenous peoples is the strength of the cultural knowledge and their communities, tribes, hapū, whānau and not the technology itself. While according to Mander (1991) there is the potential for cultural colonisation to occur again within the information 
technology structures, historically it has been proven that information technology like the "written word" has helped preserve culture. Therefore information technology can contribute to the survival and expansion of cultural knowledge as long as cultural knowledge is maintained and protected by its people.

While information technology could potentially have a similar impact on Māori knowledge, identity and representation to that of early colonisation, it has not completely deconstructed Māori culture. For example, the written word has helped preserve Māori culture. Consequently for Māori it is vital then to ensure that information surrounding Māori culture and identity today is represented comprehensively in the information technology platforms and content.

Furthermore it is important for Māori to have some control and understanding of the configuration of these technological platforms, which disseminate this information. The representation and the identity of Māori have been shaped by a multiplicity of factors arising from genealogical foundations (Durie, 1997). For Māori identity the key factors are taken to be ancestral connections through whakapapa combined with access to ancestral land as turangawaewae bound together by the ancestral language te reo Māori.

The principal of whanaungatanga can also be examined by its incorporation on the website Mana Ao Turoa Ngati Maniapoto. According to Pere (1993), the principals of whanaungatanga are the interconnectedness of all things, all generations of both sexes supporting and working alongside each other. Genealogy 'whakapapa' is an important part of whanaungatanga. It connects the whānau to the hapu and to the iwi and more so to the spiritual basis of each child's creation and creator.

The Mana Ao Turoa Ngāti Maniapoto website displays a detailed map of the rohe, whenua and all the marae that belong within the Ngāti Maniapoto iwi boundaries. In addition 
it provides an inclusive membership process so that each whānau member can easily access information about their marae and the whānau groups that whakapapa there. Furthermore it encourages whānau to participate by making valuable contributions to their whakapapa and the interconnections of whānau to hapū and to iwi. It uplifts the Ngāti Maniapoto iwi by providing a technological platform based around whanaungatanga.

From a Māori worldview perspective in the development of information technology and IPTV, the principals of kaitiakitangi, whanangatanga, manaakitanga, are a fundamental basis by which Māori could traverse the rapid growth and convergence of technology in broadcasting. The common foundations of trust, shared experiences and locality have proved to be significant in the number of levels of Māori participating in future broadcasting platforms.

According to Whitehead \& Annesley (2005), tikanga Māori provides a set of norms and values that organize and structure the relationships and behaviours of Māori people and their organizations in particular context. Iwi, hapu and whanau are important structures for many Māori and are used as a foundation for Māori to engage collectively (Whitehead \& Annesley, 2005).

For example, there are relevant case studies for Māori that provide examples of how technology and culture are working together to benefit the development of tikanga Māori and te reo Māori. For example:

- The launch of Māori Television, 2004

- Te Reo Television Channel launch, 2008

- Māori Iwi Radio

- The National Library Archives

- Te Whanake Website - www.tewhanake.co.nz

- GoggleboxTV - www.gogglebox-tv.com

- Te Ara Poutama - Faculty of Māori Development 
When examining Māori language as a cornerstone of Māori society being a taonga, at the very heart of Māori culture and identity, which must be preserved and fostered, it is important to examine the broadcasting sector, which plays an important role in increasing Māori language status, knowledge and use. This development of Iwi radio and the launch of Māori Television in 2004 increase the widespread distribution of video and audio content of te reo within Aotearoa New Zealand and therefore support the normalisation of the Māori language in the home. Thee intergenerational transmission of language is one key factor in overall Māori language revitalisation (Te Puni Kokiri, 2006). However, there has been an ongoing struggle for Māori to obtain and govern their own broadcasting avenues and channels for both radio and television.

In 1981 Ngā Kaiwhakapūmau i Te Reo was established in Wellington, which represented local iwi. The organization took a far more assertive stance toward Māori broadcasting. In 1984 the organization made a claim to the Waitangi Tribunal in regard to maintenance of te reo Māori, which included a commitment by broadcasters to foster the language.

The case rested on the Waitangi Tribunal interpretation of the Treaty of Waitangi. The claimants called on Professor Hirini Moko Mead who produced a carefully prepared submission on the meaning of Articles Two and Three of the Treaty. The general thrust of his view on Article Two of the Treaty is that the phrase ' o ratou taonga katoa' covers both the tangible and the intangible things that can be translated by the expression ' all valued customs and possessions' It was the intention of Ngā Kaiwhakapūmau i Te Reo, to use radio as a tool to help the language survive as $\mathrm{Te}$ Reo was acknowledged as a taonga.

Māori language became an official language of Aotearoa in 1986 nearly four years after Nga Kaiwhakapūmau i Te Reo began their quest (Beatson, 2004). The doors were unlocked for Māori to pursue a Crown commitment to Māori language 
broadcasting. The claimants took various legal actions in the New Zealand courts to effect this outcome (Walker, 1995).

Therefore, the role and vision of Māori Television: "Whakaata Māori, he pourewa papaho taketake kei ngā taumata o te ao" (Māori Television is a world-class indigenous broadcaster) alongside their kaupapa "Ki te whakapau kaha ki te whakaora $\mathrm{i}$ te reo Māori me nga tikanga, ma te tu motuhake, toitu momoho o Whakaata Māori hei pourewa papaho whakaaturanga" provides a significant case study to the contribution in the revitalisation of te reo Māori (Māori Television, 2010).

Māori Television has two key long-term major outcomes. Those are to significantly contribute to te reo and tikanga Māori by being increasingly valued and embraced and to be an independent national Māori television broadcaster that is successful with an assured future (Māori Television, 2010).

According to Maori Television these outcomes are interconnected by a central element, which states that the channel will support the principles and practices of tikanga and kaupapa Māori. According to the Māori television mandate, the aim of Māori television is to play a major role in revitalising language and culture that is the birthright of every Māori (Māori Television, 2010).

The new digital initiatives and platforms now make Māori Television available on the UHF band to approximately fourfifths of Māori speakers, and to all of New Zealand via SKY Television's satellite service. It will also be available now on the new digital platform Freeview. In addition, Māori Television launched its second channel 'Te Reo' in 2008.

Freeview is part of the New Zealand Government's digital strategy. Although still in progress, the Digital Strategy Creating Our Digital Future was released by the previous Labour Government in 2005. For Māori, the Digital Strategy aims to recognise the need to incorporate and assist Māori in the digital futures plans for and in New Zealand. It recognises that Māori culture is distinct and unique to Aotearoa New 
Zealand. However the digital strategy does not recognise Māori as tangata whenua, nor does it look at any aspect of the Treaty of Waitangi. There is no recognition of future ownership, control and or possession of the fibre optic broadband in fracture, let alone the services it will provide within New Zealand and globally. There is no reference to any economic forecasts, developments and benefits for Māori from the implementation of fibre optic cabling.

Furthermore, the Digital Strategy does not include any reference to the protection of the environmental surrounding the fibre optic cabling being placed underground, nor to the procedures in which the Government are taking to incorporate Māori in these processes. According to the Digital Strategy (2008), it investigates the infrastructure challenges and reforms needed for New Zealand to implement high-speed Internet broadband fibre optic connection to all New Zealanders. One of the goals in the Digital strategy outlines that by 2010 New Zealand will be in the top quarter of the OCED for broadband uptake. However, the previous Labour Government's Digital Strategy failed to incorporate is its relationship to the Treaty of Waitangi and the implications for Māori. The questions of how this will this impact on the structural, environmental and economic basis for Māori in the telecommunications sector goes unanswered.

If Government follows the Digital Strategy, then the majority of New Zealanders will benefit from the uptake of faster and more efficient broadband. The economic opportunities for Māori in the convergence of broadcasting technologies may lie in the rights holders of content and the programme producer's ability to reach consumers directly.

Māori will need to be vigilant with the Government in order to recognise its obligations under the treaty with respect to the resources of telecommunications, frequencies and fibre optic being placed in the environment. In the Treaty of Waitangi, Māori ceded governance to the British Crown, but were 
guaranteed full authority (tino rangatiratanga) over their natural, physical and metaphysical resources (Orange, 1987).

The convergence of broadcasting technologies may put Māori in a stronger position by ultimately enabling them to bypass conventional broadcasters entirely. With the ability to reach global and diffuse audiences, the real potential for Māori producers and distributors may lie in their back catalogues. However for many this may present intractable intellectual propery rights problems, which is an area that funders like Te Māngai Pāho and New Zealand on Air alongside conventional broadcasters are examining now.

Goldsmith and Wu (2006) argue that it is not wheather the technological changes in the last decade have created changes in the way human beings live or interact, but question whether those changes have had a lasting effect on how nations and their people govern themselves. The destiny of the Internet in future will reflect the interests of powerful nations and the conflicts within and between them.

Goldsmith and $\mathrm{Wu}$ (2006) go on to discuss how the world wide web has widely been viewed as the essential catalyst for contemporary globalisation. In case studies conducted with Yahoo and the Chinese Regime, Google's struggles with the French Government, eBay and fraud, Goldsmith and Wu are able to reflect the power struggles surrounding the control of the Internet and how this affects us as individuals. The Internet has widely been viewed as the essential catalyst for contemporary globalisation. In the 1990's the Internet was greeted as the fantastic new thing that would erase national borders, give rise to communal societies that invented their own rules, undermine the power of governments, however Goldsmith and $\mathrm{Wu}$ argue that these early assumptions were wrong.

The Internet turns out to illustrate the enduring power of Western hegemony surrounding law, national power, and controlling cyberspace as in real space. According to Goldsmith and Wu (2006), Internet governance can no longer 
take for granted the assertion that the Internet changes everything with respect to governmental authority and territorial jurisdiction. They examine the persistent fallacies that cyberspace has the capacity to eliminate politics and governance. Goldsmith and $\mathrm{Wu}$ state that people never fully escape the need for some kind of authority to enforce basic rules against stealing, copyright and fraud on the Internet.

In addition Bettig (1996) provides a global analysis on the historical copyright law in Western societies capitalistic and hegemonistic political system relating to intellectual property. The issues covered in Bettig's book explore the technology of videocassette recorders and the control of copyrights, the invention of cable television and the first challenge to the filmed entertainment copyright systems.

In contrast Evans (2004), states the development and application of information technologies has resulted in privatisation of domestic and family lives contributing to the process of individualisation, which separates one person, one family, one neighbourhood from another. According to many of the commercial Information Technology companies, information technology and globalisation is meant to cross borders, involve and interact with communities, Evans argues that it is in fact the opposite.

However Evans (2004) suggests there are gains to be made by individuals and organizations using information technologies but it is important for people to be critical of the hype surrounding computer mediated communication as the only way forward in the future of communication. Evan's research argues that technology itself can have no inherent qualities, but that the social circumstances are the key foundation to understanding how information and computer technologies can be accepted and adopted by communities. Evans states that communities who work together collectively, have common interests and are motivated together are crucial factors in the success or failure of initiatives surrounding the use information technologies. 
However, there is debate and controversy that Hawister and Selfe (2000) provide in a critical examination of the new online literacy practices including authoring, designing, interpreting and enacting change. Their emphasis is on these particular activities as they explore the affects both directly and indirectly on various cultures. Each chapter represents and examines online literacy practices in the specific cultures, providing critical commentary from scholars around the world.

Both Hawister and Selfe (2000) have resisted an idealistic vision of global unity within online cyberspace to celebrate the uniqueness and self defined literacy communities within their own cultures. They confront conventional ideas surrounding the relationships between literacy and technology. Hawister and Selfe claim that over the past two decades enormous changes have occurred by which information is created, exchanged and distributed due to computer networks and the Internet, which figure in global communication. They explore the cultural contexts that affect the communication within a global network system they argue is culturally transparent.

Hawister and Selfe (2000) examine the ways in which the technological platforms are culturally determined, structured and ordered. That argue that until culturally specific investigations are undertaken to determine cultural literacy practices, there is no specific conclusions or truth to the internationalness of the literary environment offered by the web. Their research is to define and clarify theories that commonly accept the premise that the web provides individuals with a neutral literacy environment within which international communications are written, explored and disseminated globally.

In conclusion the literature examined in this section shows there are significant factors relating to cultural knowledge that Māori do consider and which will impact on their future developments in IPTV and future broadcasting platforms. These consist of tikanga, te reo Māori, and kaupapa. Additionally the literature indicates where there are benefits 
and threats for Maori in the areas such as representation, exploitation, intellectual property, legalities, governance and ethical issues.

\section{Technology}

When researching literature relative to the development of IPTV technology and future broadcasting platforms, Cooper and Lovelace (2006) provide a comprehensive study. IPTV represents the convergence of broadcasting, telecommunications and information technology.

According to Cooper and Lovelace (2006), IPTV is where Broadband Meets Broadcast and is considered to be the global network television revolution. With the growth in adoption of broadband and the rising speed of connections, coupled with the improved performance of computer processors and the increasing capacity of storage, online distribution of video and audio has become a much more practical proposition globally for broadcasting businesses, telecommunication companies, television production companies and for viewers.

The network television revolution involves the convergence of communications networks and a divergence of devices that will significantly change patterns of media production, distribution and consumption. Convergence is an inevitable consequence due to the developments of technologies and the transition from the analogue to digital domain. Global convergence is causing the boundaries that once separated the media, telecommunications and information technology sectors to collapse. These three previously very separate sectors are now converging in the digital domain. At the heart of the intersecting rings of media, telecommunications and information technology, the worlds of the television, telephone and computer are no longer separated but are unified by a single digital communications medium. (Cooper \& Lovelace, 2006). 
An IPTV network is divided into three major segments: the head-end user, the network and the customer premises. The head end is where the video or audio content is aggregated, compressed and encoded for transmission on the network. For IPTV the network means broadband Internet distribution which can be copper, copper upgraded, or fibre optic. The key distinction between traditional television (Service Providers) and IPTV is the degree to which viewers can roam. Most service providers will offer a walled garden service where the user is confined to the choice of channels and on demand services that are offered and the services may only be offered to subscribers (Cooper \& Lovelace, 2006).

In contrast, many IPTV services provide an open access basis. In many cases material can also be uploaded by the viewer anywhere in the world. Choice, convenience and control are key factors for the viewer. A wide choice of channels and premium programming are desirable, as are access to niche programming that is not easily available elsewhere (Cooper \& Lovelace, 2006). Service providers are characterised as having a controlled network, which is generally available on a television player where the quality of service is guaranteed. In contrast IPTV is characterised as a public Internet network which is generally available on PC, where video and audio content is streamed over broadband with open access. Additional video and audio content can be available for download (Cooper \& Lovelace, 2006).

Users also have the ability to interact by various utility of web enhanced capabilities such as video and audio content uploads to multiple websites, image and text sharing and social networking via blogs. The distribution of television, and other audio and video services over broadband connections are complementing and ultimately competing with the viewer experience that is obtained over conventional digital satellite and traditional terrestrial and cable television (Cooper \& Lovelace, 2006). 
Internet transmission arose out of a communications phenomenon into the late twentieth century as a result of connecting computers together using a set of common standards, based on developments in digital networks. The computer networks tend to communicate by transmitting data bursts or packets. Such networks are known as packetswitched networks (Cooper \& Lovelace, 2006).

The Internet was created by enabling communication between devices connected across different networks, using a common transmission standard known as Internet protocol. It is this protocol that is the foundation to Internet television. Internet search engines, portals and other online services can rapidly reach a critical mass. They become more popular and useful as more people use them and according to Cooper and Lovelace (2006) can achieve market dominance in a matter of months. The network effect is all more powerful with services that employ social networks in which users invest their own time and resources. For instance, the growth of social networking sites such as Bebo, Facebook and Youtube have become immensely popular in a short space of time (Cooper \& Lovelace, 2006).

Prior to the rapid growth of Internet transmission, television broadcast transmission was achieved via analogue broadcasting networks and their relevant technological structures. Analogue broadcasting originally provided a highly efficient means of delivering the same signal to an unlimited number of simple receivers. The audience tuned in like radio to a particular channel to listen and watch a programme (Cooper \& Lovelace, 2006).

The programmes were organised into a relatively restricted linear schedule. The technology of transmission imposed the form and function of radio and television programming in the linear schedules of a limited number of competing channels. The broadcast networks were primarily concerned with oneway delivery of multiple channels of scheduled programming 
to many receivers at the same time (Cooper $\&$ Lovelace, 2006). From analogue broadcasting transmission came broadcast transmission on digital platforms, which according to Cooper and Lovelace was largely driven by the need to create more channels, to provide premium and special interest programming. By converting signals into digital form, they could encode and compress more efficiently, enabling more services to be distributed. However the basic structure of radio and television as discrete linear channels was unchanged globally.

There are limitations to the speed and quality in which IPTV can be viewed in New Zealand because of the limited access to faster broadband services. According to Drinnan (2008) 'Telecoms lobby puts its election manifesto', which included Tuanz strategy to galvanise political action around the provision of fibre optic cable to promote the broadband Internet connections in New Zealand. Tuanz (2009) states that politicians need to go further than the Telecom spilt into three divisions to improve services and ensure that New Zealand is not left behind in development of the telecoms based economies. This will have an immense impact on the growth of IPTV and the delivery of video and audio services over the Internet. For Māori, it will be important to keep abreast of the telecommunications private sector and the New Zealand Government's policies on broadband. (Drinnan, 2008)

Many leading broadcasters around the world are experimenting with the new distribution opportunities. The range from gaining carriage deals with telecommunications groups for their new services to pursue a range of online streaming and download options. Currently there is a confusion of format technologies and business models (Cooper $\&$ Lovelace, 2006). For the development of Māori in IPTV, it will be important to examine global trends the successful global IPTV scenarios, distribution models and advances in technologies, keeping in mind the implementation of faster broadband in New Zealand. 
Norris and Pauling (2008) provide different aspects to the digital revolution, with changes in technology in New Zealand and internationally. In their report 'The Digital Future and Public Broadcasting' they denote Chapter 2 to technology developments. The chapter provides comprehensive information and statistics on how people respond to the technology and its opportunities, even though some of the conclusions from the statistics conflict or are unclear.

In Chapter 3, the data charts New Zealand's progress to digital, and Chapter 5, which examines public broadcasting in New Zealand, following discussion of the principles of public broadcasting in Chapter 4. Chapter 6 deals with the opportunities the digital revolution has opened up for the expansion of the archives both internationally and in New Zealand.

The information in this literature review critically appraises valid studies and directly uses the information to identify areas of controversy for Māori. What is evident is that further research into the development of Internet protocol television for Māori needs to be undertaken as much of the literature examines global indigenous perspectives.

A more in depth look and collection of primary data of case studies such as Te Whanake Online and Māori Television will provides insights into cultural knowledge, the technological and economic indicators which may facilitate development of IPTV and future broadcasting platforms for Māori. The roll out of faster broadband will also have an immense impact on the way in which IPTV is delivered to New Zealand audiences. The New Zealand government policies and digital strategy will need to be explored further in depth.

\section{Economy}

The commercial aspects of ownership by telecommunications in IPTV will need to be investigated further to examine where Māori are positioned in the 
development of fundamental broadcasting technology platforms for economic development. The literature examined looks specifically at New Zealand. This includes the roles played by:

- $\quad$ NZ On Air

- Te Māngai Pāho

- Te Huarahi Trust Māori Spectrum

The New Zealand Broadcasting Act has been amended to enable NZ On Air and Te Māngai Pāho to move into funding online projects and the opportunity to develop new media content for new platforms. NZ On Air was considering how it could gain a stronger public service presence on the web. NZ On Air's digital strategy was to establish a Digital Content Partnership Fund of $\$ 1$ million as a proactive recognition of the demands and opportunities of the digital era. Applications to NZ On Air Digital Partnership Fund, was sought by the company to expand the production of a digital interactive channel that focuses on youth, Māori and entertainment programming (NZ On Air, 2009).

The Partnership Fund suggested that a project like NZ On Line requires a concerted approach across a number of different agencies (public libraries, art galleries, archives and museums) all concerned with the promotion and development of digital content. NZ On Air's digital strategy and the establishing of its Digital Content Partnership Fund is a proactive recognition of the demands and opportunities of the digital era (Norris \& Pauling, 2008).

Currently Te Māngai Pāho (TMP) does not have a specific policy on IPTV and other digital platforms. One of the reasons for this is that although the legislative authority was extended to allow TMP to invest in 'new media' they are not provided with any additional funding for that domain. As a result any money invested in this arena will need to be taken from our existing Television and Radio programmes. Consequently, TMP have been taking a slower approach. TMP are currently developing a policy framework and in August or September 
2010 will publish a small request for proposal (RFP) for digital initiatives (Parr, 2010).

In May 2000, the New Zealand Crown announced it would allocate to Māori a block of third generation (3G) spectrum radio frequency under what the New Zealand Government saw as favourable purchase terms. The block was to be uplifted after the conclusion of the Crown's 3G auction. The Crown also announced $\$ 5$ million would be available to fund establishment costs, in particular, the cost of finding and establishing a relationship with a commercial partner.

The Te Huarahi Tika Trust was established on 3 July 2000 , in order to secure a commercial relationship with the crown for the allocation of $3 \mathrm{G}$ spectrums, which represented the interests of Māori. It included legal, commercial and technical advisors. The Te Huarahi Tika Trust established a trading trust (Hautaki Trust) operated by a company set up to act as trustee (Hautaki Limited). Hautaki Limited has responsibility for securing a commercial arrangement to leverage and maximise access to the 3G-management right. The separate trading trust provided a commercial entity capable of developing a viable relationship with a commercial partner in order to deliver long-term benefits to Māori (Huarahi Annual Report, 2009).

When examining a literary global overview of information technology and its rapid growth there are distinctive threats and opportunities of converging communications that conventional Māori broadcasters, independent Māori production companies, Māori information technology businesses, iwi, hapū and whānau will need to examine in order protect and secure the cultural representation and future developments for Māori in IPTV. These includes:

- Intellectual Property Protection

- E-commerce

Frankel and McLay (2002) offered a discussion of the 
emerging law applying to computer technology and the Internet, and consider issues of particular importance to New Zealand, such as the intellectual property rights of Māori, in their book 'Intellectual property in New Zealand'. The text covers traditional intellectual property law topics such as the laws of copyright, patents, registered designs and trademarks. Additionally Al-Qirim (2004), provides investigation into Electronic commerce in small to medium-sized enterprises: Frameworks, issues and implications addresses ecommerce issues in small to medium-sized enterprises (SMEs) in a global setting. The book aims at addressing issues that are of importance to researchers, to students, and to professionals interested in the ecommerce field in SMEs. Hence, interests in addressing issues pertaining to theory and to practice.

The development and increasing take-up of electronic technologies such as the Internet present businesses with new and exciting opportunities in e-commerce, such as exposure to worldwide markets and greater automation of existing business processes. New Zealand businesses and legal professionals need guidance across the broad spectrum of laws that apply to e-commerce, in both New Zealand and global contexts. Simpson Gierson (2002) 'A guide to Ecommerce law in New Zealand' is a topical overview of the law and issues relating to e-commerce in New Zealand. It combines the relevant principles, legislation, and case law with practical guidance for businesses engaging, or intending to engage in e-commerce.

\section{Conclusion}

In conclusion, the literature review has examined research that has been undertaken in the field of Internet protocols surrounding technology, Māori culture, legal, governance, economic and ethical issues in order to explore the development of Internet protocol television for Māori in Aotearoa New Zealand. 


\section{Bibliography}

Al-Qirim, N. (2004). Electronic commerce in small to medium-sized enterprises: Frameworks, issues and implications. Hershey, Penn: Idea Group Publishing.

Beatson, D. (2004). Television in New Zealand:Programming the nation. Auckland: Oxford University Press, 76 - 92.

Bettig, R. (1996). Copyrighting Culture:The political economy of intellectual property. Colorado: Harper Collins.

Evans, K. (2004). Maintaining community in the information age. Hampshire, New York: Palgrave MacMillan.

Frankel,S. \& McLay, G (2002). Intellectual property in New Zealand. London:LexisNexis Butterworths.

Front of the Box Productions Ltd. (2009). Retrieved June, 2009 from www.frontofthebox.co.nz

Goldsmith, J.\& Wu, T. (2006). Who controls the Internet: Illusions of a borderless world. New York: Oxford University Press.

GoggleboxTV. (2009). Retrieved March, 2009 from www.goggleboxtv.com

Hawisher,G. \& Selfe, C. (Eds.). (2000). Global literacies and the worldwide web. London: Routledge.

Iseke-Barnes, J., \& Sakai, C. (2003). Indigenous knowledges, representations of indigenous peoples on the Internet, and pedagogies in a case study in education: Questioning using the Web to teach about indigenous peoples. Journal of Educational Thought, 37, 197-232.

Kamira, R. (2003). Te Mata o te Tai - The Edge of the Tide: Rising Capacity in Information Technology of Māori in Aotearoa-New Zealand. [Electronic Version] 21, 465-475.

Lovelace, G. \& Cooper,W. (2006). IPTV Guide - Delivering audio and video over broadband [Electronic Version]. Retrieved from www.informitv.com

Mander, J. (1991). In the absence of the sacred: The failure of technology and the survival of the Indian Nations. an Franciso, CA: Sierra Club Books.

Māori Television. (2010) Mãori Television Pänui Whäinga 2010-2013, Statement of Intent. Retrieved 2010 from http://corporate.māoritelevision.com

Mead, L.T.R. (1996). Te aho ot te kakahu matauranga: The multiple layers of struggle by Mãori in education. Unpublished doctoral dissertation. The University of Auckland.

Ministry of Economic Development. (2010) Intellectual Property Office. Retreived December, 2010 from http://www.iponz.govt.nz/cms/what-is-ip/what-is-intellectualproperty

Ministry of Economic Development, (2009). Digital Futures Planning 
for Digital Television and New Uses, A Discussion Paper.

Norris, P and Pauling, B (2008). The Digital Future and Public Broadcasting. A research report prepared for New Zealand On Air. Wellington.

NZ On Air. (2010) New Zealand On Air Statement of Intent. Retrieved May, 19, 2010, from http://www.tmp.govt.nz/about/SOI_10_FA_Web.pdf

Orange, C. (1987). The Treaty of Waitangi. Wellington, New Zealand: Allen and Urwin New Zealand Limited.

Simpson Grierson.x-tech Group. (2002). Guide to electronic commerce law in New Zealand. Wellington:Thomson Brookers.

Parr, L. (2010, July 21). Personal Email response to Te Māngai Pāho future broadcasting platforms.

Pere, R. (1984). Ako: Concepts and learning in Māori tradition. Reprinted 1994, Te Kohanga Reo Trust. Wellington.

Te Huarahi Tika Trust, (2009). Te Huarahi Tika Trust Annual Report 2009. Retrieved 2010, from http://www.thtt.co.nz/

Te Mana Ao Turoa Ngāti Maniapoto. (2009). Retrieved March, 2009 from http://www.manaaoturoa.com/maniapoto.php

Te Māngai Pāho. (2010) Te Māngai Pāho Statement of Intent, Tauaki Whakamaunga Atu 2010-2015. Retrieved 2010, from http://www.tmp.govt.nz/about/SOI_10_FA_Web.pdf

Te Puni Kokiri. (2000). Māori research development kaupapa Māori principals and practices. A literature review. Prepared by Linda Tuhiwai Smith, Auckland University and Dr Papaarangi Reid, University of Otago.

Te Puni Kokiri. (2010). Retieved June, 2010 from http://www.tpk.govt.nz/en/

Te Whanake. (2010) Te Whanake Online. Retrieved October, 2010 from http://www.tewhanake.māori.nz/

Te Whare Runanga o Raukawa radio interview (1995). Interview with P.Walker [Radio Broadcast].

The Digital Strategy. (2005) Creating Our Digital Future. Retrieved June, 2009 from www.digitalstrategy.govt.nz

Whitehead, J \& Annesley, B (2005). The context for Māori economic development: A Background Paper for the Hui Taumata. Wellington: New Zealand Treasury. 